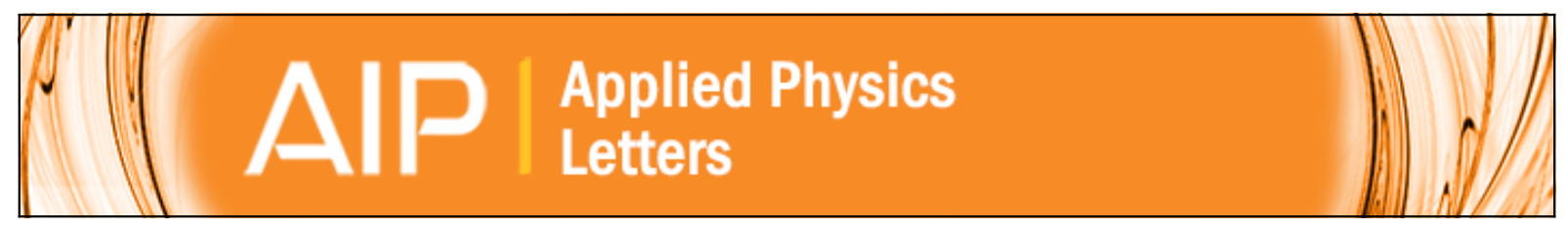

\title{
Enhanced initial growth of atomic-layer-deposited metal oxides on hydrogen- terminated silicon
}

Martin M. Frank, Yves J. Chabal, Martin L. Green, Annelies Delabie, Bert Brijs, Glen D. Wilk, Mun-Yee Ho, Elisa B. O. da Rosa, Israel J. R. Baumvol, and Fernanda C. Stedile

Citation: Applied Physics Letters 83, 740 (2003); doi: 10.1063/1.1595719

View online: http://dx.doi.org/10.1063/1.1595719

View Table of Contents: http://scitation.aip.org/content/aip/journal/apl/83/4?ver=pdfcov

Published by the AIP Publishing

\section{Articles you may be interested in}

Interface studies of GaAs metal-oxide-semiconductor structures using atomic-layer-deposited $\mathrm{HfO} 2 / \mathrm{Al} 2 \mathrm{O} 3$ nanolaminate gate dielectric

Appl. Phys. Lett. 91, 142122 (2007); 10.1063/1.2798499

In situ infrared spectroscopy of hafnium oxide growth on hydrogen-terminated silicon surfaces by atomic layer deposition

Appl. Phys. Lett. 87, 133103 (2005); 10.1063/1.2058226

Island growth in the atomic layer deposition of zirconium oxide and aluminum oxide on hydrogen-terminated silicon: Growth mode modeling and transmission electron microscopy

J. Appl. Phys. 96, 4878 (2004); 10.1063/1.1787624

Density functional theory study of $\mathrm{HfCl} 4, \mathrm{ZrCl} 4$, and $\mathrm{Al}(\mathrm{CH} 3) 3$ decomposition on hydroxylated $\mathrm{SiO} 2$ : Initial stage of high-k atomic layer deposition

Appl. Phys. Lett. 83, 542 (2003); 10.1063/1.1587261

Suppressed crystallization of $\mathrm{Hf}$-based gate dielectrics by controlled addition of $\mathrm{Al} 2 \mathrm{O} 3$ using atomic layer deposition

Appl. Phys. Lett. 81, 4218 (2002); 10.1063/1.1522826

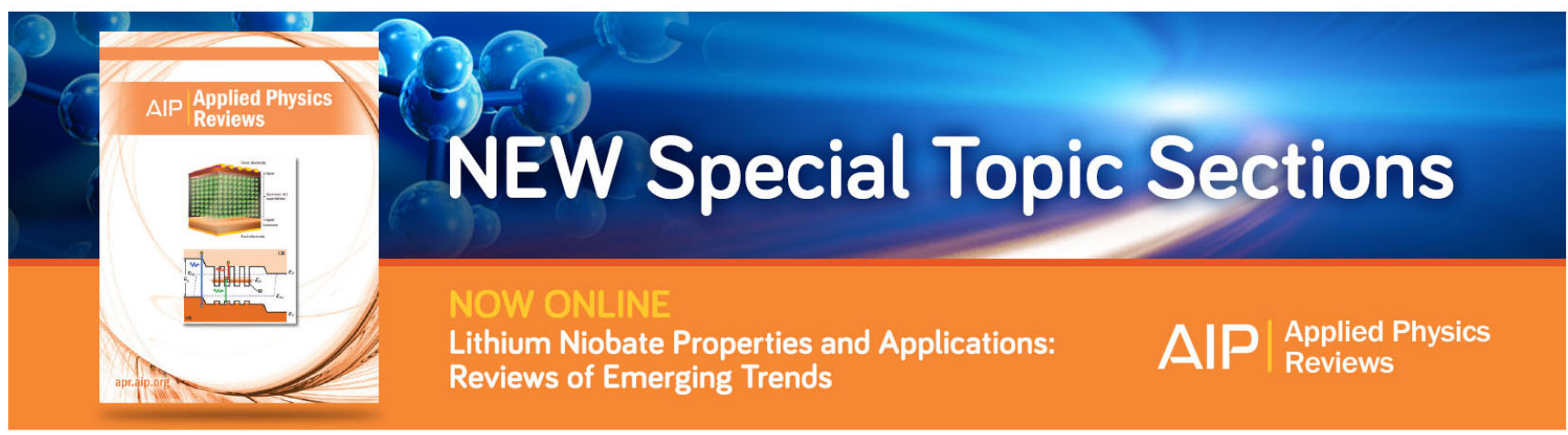




\title{
Enhanced initial growth of atomic-layer-deposited metal oxides on hydrogen-terminated silicon
}

\author{
Martin M. Frank ${ }^{a), b)}$ and Yves J. Chabal ${ }^{\text {b) }}$ \\ Rutgers University, Department of Chemistry and Chemical Biology, Piscataway, New Jersey 08854 \\ Martin L. Green, ${ }^{\text {b) }}$ Annelies Delabie, and Bert Brijs \\ IMEC, Kapeldreef 75, B-3001 Leuven, Belgium \\ Glen D. Wilk ${ }^{\mathrm{c}}$ and Mun-Yee $\mathrm{Ho}^{\mathrm{d})}$ \\ Agere Systems, Murray Hill, New Jersey 07974 \\ Elisa B. O. da Rosa, Israel J. R. Baumvol, ${ }^{\mathrm{e}}$ and Fernanda C. Stedile \\ Instituto de Física and Instituto de Química, UFRGS, Porto Alegre, RS, Brazil 91509-900
}

(Received 21 February 2003; accepted 28 May 2003)

\begin{abstract}
A route is presented for activation of hydrogen-terminated $\mathrm{Si}(100)$ prior to atomic layer deposition. It is based on our discovery from in situ infrared spectroscopy that organometallic precursors can effectively initiate oxide growth. Narrow nuclear resonance profiling and Rutherford backscattering spectrometry show that surface functionalization by pre-exposure to $10^{8}$ Langmuir trimethylaluminum at $300{ }^{\circ} \mathrm{C}$ leads to enhanced nucleation and to nearly linear growth kinetics of the high-permittivity gate dielectrics aluminum oxide and hafnium oxide. (C) 2003 American Institute of Physics. [DOI: 10.1063/1.1595719]
\end{abstract}

As $\mathrm{SiO}_{2}$, the traditional gate dielectric in field effect transistors, approaches its ultimate thickness limit, alternative materials are required to replace $\mathrm{SiO}_{2}$ and continue device scaling. High- $\kappa$ materials such as $\mathrm{Al}_{2} \mathrm{O}_{3}$ and $\mathrm{HfO}_{2}$ are attractive candidates, the more so if they can be deposited directly on silicon with monolayer thickness and uniformity control. In atomic layer deposition (ALD), a promising and highly manufacturable technique, a metal precursor and an oxidizing agent are brought to the surface in alternating pulses, separated by an inert gas (e.g., $\mathrm{N}_{2}$ ) purge. $\mathrm{H}_{2} \mathrm{O}$ is the most commonly used oxidizing agent while $\mathrm{Al}\left(\mathrm{CH}_{3}\right)_{3}$ [trimethylaluminum (TMA)] and $\mathrm{HfCl}_{4}$ are the preferred metal precursors for $\mathrm{Al}_{2} \mathrm{O}_{3}$ and $\mathrm{HfO}_{2}$, respectively. Growth is based on self-terminating surface reactions. ${ }^{1}$ Compounds can thus be deposited on complex geometries with a maximum growth rate of one monolayer per pulse, thereby allowing conformal growth with thickness and uniformity control at the angstrom level.

An abrupt Si/high- $\kappa$ interface is desirable to maximize gate stack capacitance. Therefore, growth on H-passivated $\mathrm{Si}$ $(\mathrm{H} / \mathrm{Si})$ has been attempted ${ }^{2-9}$ instead of growth on thin $\mathrm{SiO}_{2}$ buffer layers. On H/Si, however, growth is nonlinear, exhibiting an incubation period due to inhomogeneous nucleation. ${ }^{5,6,8,9}$ Rough films result from the islanded growth mode and unwanted interfacial $\mathrm{SiO}_{2}$ or silicates are formed. ${ }^{5-7}$

In order to improve the initial ALD growth of monolayer thick films through an understanding of the nucleation and growth mechanism, we have recently conducted in situ IR absorption studies of the first few ALD cycles of $\mathrm{Al}_{2} \mathrm{O}_{3}$ on

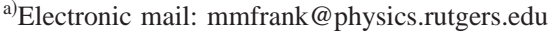

b) Also at: Agere Systems, Murray Hill, NJ 07974, and Allentown, PA 18109.

${ }^{c}$ Present address: ASM America, Phoenix, AZ 85034

d) Present address: Chartered Semiconductor Mfg. Ltd., Singapore 738406.

e) Present address: Universidade de Caixas do Sul, RS, 92670 Brazil.
}

$\mathrm{H} / \mathrm{Si}^{10}{ }^{10}$ We have thus shown that growth is not initiated by water, as commonly believed, but rather is initiated by extended metal precursor (TMA) pre-exposure. In the present work, we use this information and combine other experimental techniques to demonstrate that proper functionalization of $\mathrm{H} / \mathrm{Si}$ by TMA dramatically improves the growth characteristics of $\mathrm{Al}_{2} \mathrm{O}_{3}$ and $\mathrm{HfO}_{2}$ films.

We perform in situ and ex situ film characterization. For in situ work, emphasis is placed on probing surface reactions under high enough exposures to achieve completion of surface reactions, which is particularly important for looking at relatively stable $\mathrm{H} / \mathrm{Si}$ surfaces. This is done in a home-built ALD reactor ${ }^{11}$ equipped with a shutter/purge arrangement to protect the IR windows from comparatively high water and TMA partial pressures (10 and 1 mbar, respectively, in $\mathrm{N}_{2}$ carrier gas at 1 bar; exposures up to $4 \times 10^{4}$ times higher than used in standard commercial processes; standard exposures are, e.g., $4 \times 10^{3} \mathrm{~L}$ TMA and $10^{4} \mathrm{~L}$ water; $1 \mathrm{~L}=1$ Langmuir $=10^{-6}$ Torr $\mathrm{s}$ ). The IR transmission measurements are carried out at $70^{\circ}$ off-normal incidence, with the sample temperature maintained at $50{ }^{\circ} \mathrm{C}$, following each precursor exposure at $300^{\circ} \mathrm{C}$. Use of $\mathrm{D}_{2} \mathrm{O}$ instead of $\mathrm{H}_{2} \mathrm{O}$ ensures that all IR bands are separated from the signals caused by trace amounts of water in the optical system, and does not affect growth chemistry. ${ }^{10}$

Films studied by ex situ techniques are grown in commercial ALD reactors (ASM Pulsar2000TM). Rutherford backscattering spectrometry (RBS) is performed at IMEC to determine the areal density of $\mathrm{Hf}$ in $\mathrm{HfO}_{2}$ films. To enhance the sensitivity to $\mathrm{Hf}$, the beam energy was decreased to 1 $\mathrm{MeV}$. In the case of the $\mathrm{Al}_{2} \mathrm{O}_{3}$ films, the small mass difference between $\mathrm{Al}$ and $\mathrm{Si}$ precludes the separation of their RBS signals. The Al areal density is therefore determined from the area under excitation curves generated by narrow nuclear resonance profiling (NRP), ${ }^{12,13}$ calibrated with two 


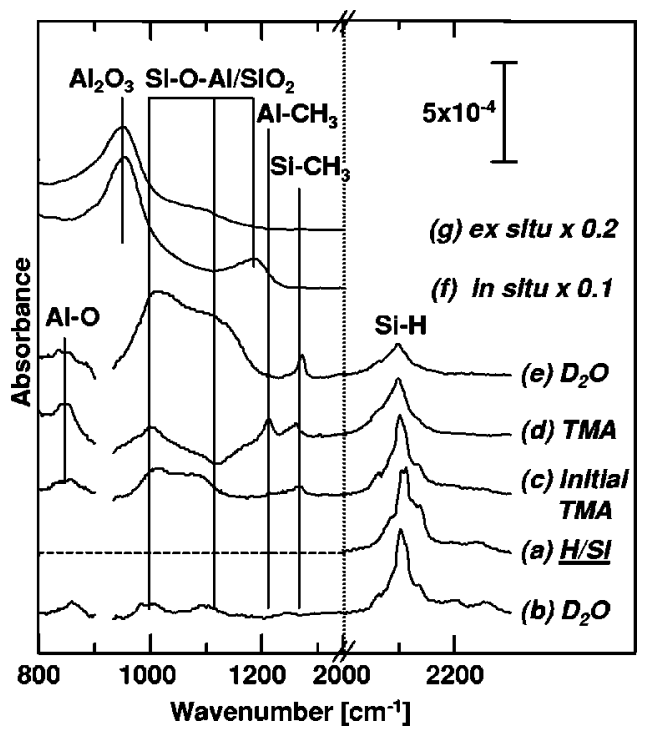

FIG. 1. Transmission IR spectra of H-terminated $\mathrm{Si}(100)$ before and after exposure to TMA-water cycles. Bottom spectra taken in situ in a model reactor (growth on both front and back surfaces): (a) pristine $\mathrm{H} / \mathrm{Si}$; (b) $\mathrm{H} / \mathrm{Si}$ exposed to an extended $\mathrm{D}_{2} \mathrm{O}$ pulse; (c) $\mathrm{H} / \mathrm{Si}$ exposed to an intermediate amount of TMA (corresponding to a $\sim 30 \mathrm{~s}$ pulse in a commercial reactor), followed by extended pulses of (d) TMA and (e) $\mathrm{D}_{2} \mathrm{O}$; and (f) $\mathrm{H} / \mathrm{Si}$ exposed to 16 TMA- $\mathrm{D}_{2} \mathrm{O}$ cycles. Top spectrum $(\mathrm{g})$ taken ex situ from a 34 cycle film grown in a commercial ALD reactor, utilizing an initial $3600 \mathrm{~s}$ TMA pulse (growth on one wafer surface only; spectra (f) and (g) scaled to ensure comparability of the intensities). Reference surface for oxide phonon region: $\mathrm{H}$-terminated $\mathrm{Si}$; and for $\mathrm{Si}-\mathrm{H}$ stretching region: $\mathrm{Si}$ with native $\mathrm{SiO}_{2}$. A signal at $\sim 920 \mathrm{~cm}^{-1}$ is due to $\mathrm{Si}-\mathrm{H}$ bending modes of the $\mathrm{H} / \mathrm{Si}(100) \mathrm{ref}$ erence surface and has been removed for clarity.

standard samples. This is a technique so far not applied to the study of monolayer-thick films. The $992 \mathrm{keV}$ resonance of the ${ }^{27} \mathrm{Al}(p, \gamma){ }^{28} \mathrm{Si}$ reaction is used and the $3 \mathrm{MV}$ Tandetron accelerator at Porto Alegre delivers the proton beam. The uncertainty in areal density is estimated as $\pm 15 \%$.

The IR spectra (a) - (g) in Fig. 1 summarize the key findings concerning $\mathrm{Al}_{2} \mathrm{O}_{3}$ nucleation and growth chemistry on HF-etched $\mathrm{Si}(100) .{ }^{10}$ The initial H/Si surface (a) is atomically rough (exhibiting double-layer roughness), with a broad and structured $\mathrm{Si}-\mathrm{H}$ stretching band centered at $2110 \mathrm{~cm}^{-1}$, associated with mono-, di-, and trihydrides, ${ }^{14}$ and a weaker band at $2250 \mathrm{~cm}^{-1}$ arising from oxidized $\mathrm{Si}-\mathrm{H}^{15}$ Very large $\mathrm{D}_{2} \mathrm{O}$ exposures at $300^{\circ} \mathrm{C}[$ (b) 5 $\left.\times 10^{8} \mathrm{~L}\right]$ leave the surface nearly unchanged chemically: ${ }^{16}$ the $\mathrm{Si}-\mathrm{H}$ stretch signal is unaffected, except for a few percent of isotopic $\mathrm{Si}-\mathrm{H}$ to $\mathrm{Si}-\mathrm{D}$ exchange (not shown), and at most $0.1 \AA \mathrm{SiO}_{2} \quad\left(5 \times 10^{13} \mathrm{O}\right.$ ions per $\mathrm{cm}^{2}$, $\left.\sim 1000-1200 \mathrm{~cm}^{-1}\right)^{17}$ and 0.02 monolayers of OD groups $\left(1.3 \times 10^{13}\right.$ OD per $\mathrm{cm}^{2}$, not shown) are formed. ${ }^{10}$

In contrast, TMA reacts with $\mathrm{H} / \mathrm{Si}(100)$ at $300{ }^{\circ} \mathrm{C}$. An initial TMA exposure [Fig. $1(\mathrm{c}), 2 \times 10^{5} \mathrm{~L}$ ] predominantly forms $\mathrm{Si}-\mathrm{CH}_{3}\left(1266 \mathrm{~cm}^{-1}\right)$ at $\mathrm{Si}$ defect sites, and higher TMA exposures [(d) $\left.5 \times 10^{7} \mathrm{~L}\right]$ give rise to $\mathrm{Al}-\mathrm{CH}_{3}$ species $\left(1217 \mathrm{~cm}^{-1}\right) .{ }^{10}$ While oxidized TMA, probably due to gas impurities, leads to the formation of interfacial $\mathrm{Si}-\mathrm{O}-\mathrm{Al}$ bond arrangements (800 and $\left.1000-1100 \mathrm{~cm}^{-1}\right),{ }^{10,18}$ inadvertent $\mathrm{SiO}_{2}$ formation is limited to less than $0.25 \AA$. Once the $\mathrm{H} / \mathrm{Si}(100)$ surface has been functionalized by TMA, a water pulse (e) replaces Al-bonded $\mathrm{CH}_{3}$ (but not Si-bonded $\mathrm{CH}_{3}$ ) by $\mathrm{OD}$ and gives rise to subsurface $\mathrm{SiO}_{2}$. In the subsequent cycles (f), amorphous $\mathrm{Al}_{2} \mathrm{O}_{3}$ is grown, while addi-

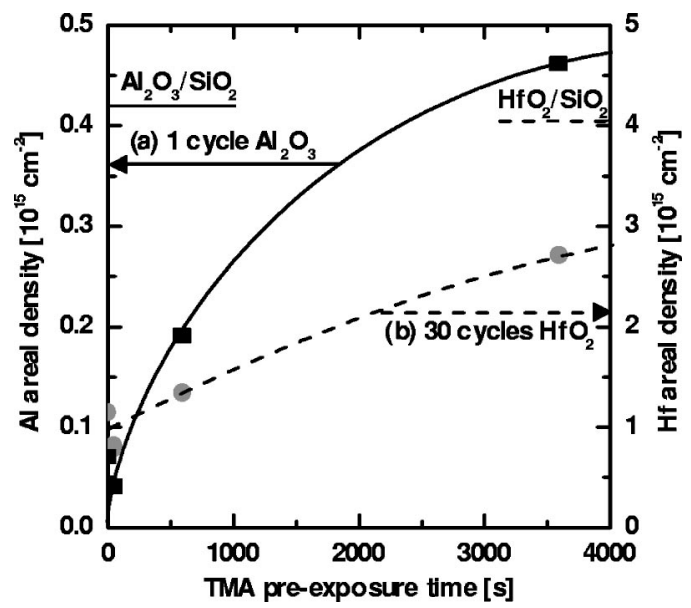

FIG. 2. (a) Left-hand axis: $\mathrm{Al}$ areal density dependence, as determined by NRP, on the duration (0.1-3600 s) of the TMA pre-exposure in a single TMA-water cycle, compared with the $\mathrm{Al}$ areal density after a regular cycle on a hydrous chemical oxide starting surface (" $\mathrm{Al}_{2} \mathrm{O}_{3} / \mathrm{SiO}_{2}$ ") ). (b) Righthand axis: Hf areal density dependence, as determined by RBS, on the duration of the TMA pulse in a single TMA-water cycle and 30 subsequent $\mathrm{HfCl}_{4}$-water cycles, compared with the $\mathrm{Hf}$ areal density after 30 $\mathrm{HfCl}_{4}$-water cycles on pristine $\mathrm{H} / \mathrm{Si}$ (" $0 \mathrm{~s}$ ") and on a hydrous chemical oxide starting surface (" $\mathrm{HfO}_{2} / \mathrm{SiO}_{2}$ "). The lines are guides for the eye.

tional subsurface $\mathrm{Si}$ oxidation is catalyzed by interfacial aluminum. ${ }^{10} \mathrm{Al}_{2} \mathrm{O}_{3}$ films grown with a long initial TMA pulse in a commercial ALD reactor $\left[(\mathrm{g}) 3600 \mathrm{~s}, 10^{8} \mathrm{~L}\right]$ are very similar to those from our model reactor. The much lower water exposures employed in the commercial reactor $\left(10^{4} \mathrm{~L}\right)$, however, guarantee that the $\mathrm{SiO}_{2}$ interlayer thickness is smaller. ${ }^{10,11}$

We conclude that water exposure has essentially no effect on $\mathrm{H} / \mathrm{Si}$, while regular and oxidized TMA species strongly modify the surface and initiate oxide growth when supplied in quantities exceeding what is typically used in the commercial process. Consequently, we expect a more homogeneous nucleation and hence more linear growth after a large initial TMA exposure.

To test this conjecture, we use NRP to measure the $\mathrm{Al}$ areal density in $\mathrm{Al}_{2} \mathrm{O}_{3}$ films grown in a commercial ALD reactor under different initial TMA pulse conditions. Figure 2(a) shows that the $\mathrm{Al}$ areal density deposited on $\mathrm{H} / \mathrm{Si}$ during the first cycle increases with increasing TMA exposure time, confirming surface modification by the TMA pulse. After a 3600 s TMA pulse $\left(10^{8} \mathrm{~L}\right)$, the $\mathrm{Al}$ areal density reaches values observed for standard TMA exposures $\left(4 \times 10^{3} \mathrm{~L}\right)$ of a hydrous chemical oxide. ${ }^{19}$ Such chemical oxide contains a high concentration of $\mathrm{OH}$ sites that are very reactive with metal precursors, which leads to nearly linear high- $\kappa$ growth. ${ }^{6,9}$ This is confirmed by NRP data for $\mathrm{Al}_{2} \mathrm{O}_{3}$ (Fig. 3).

The key finding reported in Figs. 2 and 3 is direct proof that a similar, complete nucleation can also be achieved on $\mathrm{H} / \mathrm{Si}$ by long TMA pre-exposure. While the standard $\mathrm{H} / \mathrm{Si}$ starting surface exhibits the well-known incubation period with a delay of about 15 cycles before the onset of linear growth (Fig. 3, bottom curve), ${ }^{5,6,8}$ this incubation time is shortened and growth gradually approaches nearly linear characteristics as the length of the initial TMA pulses increases to $3600 \mathrm{~s}$. Enhanced oxide nucleation on TMAmodified $\mathrm{H} / \mathrm{Si}$ is confirmed by ellipsometry. We note that there is no noticeable increase in electrical leakage (e.g., by 


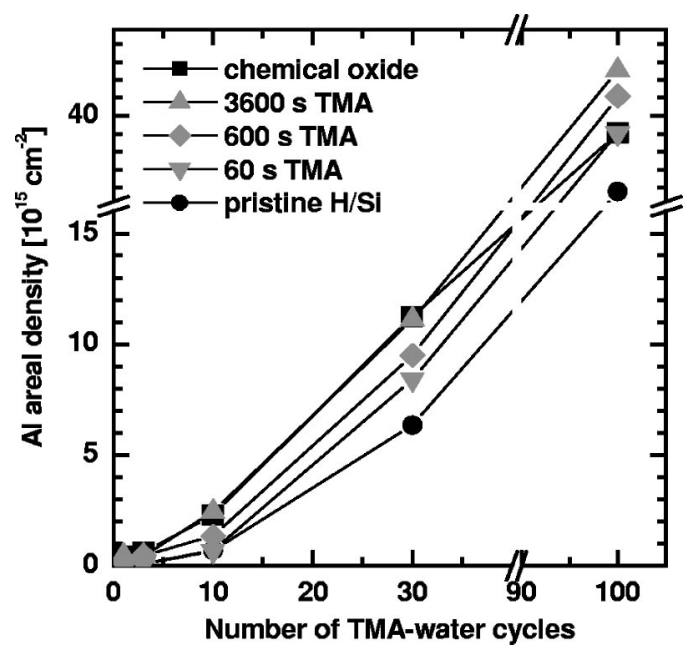

FIG. 3. Al areal density dependence on the number of TMA-water cycles for different starting surfaces: pristine $\mathrm{H} / \mathrm{Si}(100), \mathrm{H} / \mathrm{Si}(100)$ pre-exposed to TMA pulses of various durations, and a hydrous chemical oxide. The lines are guides for the eye.

C contamination) compared to $\mathrm{Al}_{2} \mathrm{O}_{3}$ films grown on pristine $\mathrm{H} / \mathrm{Si}$.

Based on our IR and NRP data, a clear picture of $\mathrm{Al}_{2} \mathrm{O}_{3}$ nucleation and growth on $\mathrm{H} / \mathrm{Si}$ surfaces emerges. A short (e.g., $60 \mathrm{~s}$ ) TMA pulse deposits only very little $\mathrm{Al}$ [Fig. 2(a)], while many $\mathrm{Si}-\mathrm{CH}_{3}$ groups are formed [Fig. 1(c)]. These Si-bonded methyl groups are not reactive with water during the initial growth cycles [Fig. 1(e)], thus providing a passivation at least as effective as hydrogen. ${ }^{20}$ Accordingly, during the first 10 ALD cycles following a $60 \mathrm{~s}$ TMA pulse, the growth rate is close to that on pristine $\mathrm{H} / \mathrm{Si}$ (Fig. 3). At later growth stages, however, we observe the gradual decomposition of most $\mathrm{Si}-\mathrm{CH}_{3}$ [Fig. 1(f)]. Reactive $\mathrm{Si}$ sites are thus created, resulting in an increased growth rate (Fig. 3). If, instead, longer TMA pre-exposures are used at the onset, then $\mathrm{Al}-\mathrm{CH}_{3}$ is formed as well [Fig. 1(d)]. Such $\mathrm{Al}-\mathrm{CH}_{3}$ sites readily react with water to form hydroxylated $\mathrm{Al}_{2} \mathrm{O}_{3}$. For long TMA pre-exposures (3600 s), nucleation is therefore enhanced after the very first pulse (Fig. 3), supporting linear $\mathrm{Al}_{2} \mathrm{O}_{3}$ growth.

TMA-induced activation of $\mathrm{H} / \mathrm{Si}$ is expected to be of general use for water-based dielectric growth, as hydroxyl groups present after the subsequent water pulse constitute reactive sites for many metal precursors. We have tested this hypothesis for the case of $\mathrm{HfO}_{2}$ deposition from $\mathrm{HfCl}_{4}$ and water precursors. We find that the $\mathrm{Hf}$ areal density deposited after $30 \mathrm{HfO}_{2}$ ALD cycles on TMA-water pre-exposed $\mathrm{H} / \mathrm{Si}$ surfaces increases with increasing duration of the TMA pulse [Fig. 2(b)], approaching that on a hydrous chemical oxide. This shows that TMA pre-exposure of $\mathrm{H} / \mathrm{Si}$ results in a better $\mathrm{HfO}_{2}$ surface coverage and probably also in a reduced film roughness. The $\sim 35 \%$ lower $\mathrm{HfO}_{2}$ growth rate after a 3600 s TMA pre-exposure compared to that on a hydrous chemical oxide may be due to the presence of some $\mathrm{Al}$ oxide sites that are less reactive to $\mathrm{HfCl}_{4}$ than hydroxyl groups. TMA, by contrast, can dissociate on hydroxyl-free oxide sites, ${ }^{21}$ which would explain the differences in $\mathrm{Al}_{2} \mathrm{O}_{3}$ and $\mathrm{HfO}_{2}$ growth enhancement [compare the growth evolution for 30 cycles of $\mathrm{Al}_{2} \mathrm{O}_{3}$ in Fig. 3 to that of $\mathrm{HfO}_{2}$ shown in Fig. 2(b)].

In conclusion, an in situ approach to understanding surface chemistry in ALD has enabled us to propose a route for $\mathrm{Si}$ surface functionalization, based on extended TMA preexposure of $\mathrm{H}$-terminated $\mathrm{Si}$. $\mathrm{Al}_{2} \mathrm{O}_{3}$ and $\mathrm{HfO}_{2}$ films grown on TMA-modified surfaces exhibit enhanced initial growth kinetics, approaching linear growth. The proposed combination of TMA and $\mathrm{HfCl}_{4}$ precursors may become an important ingredient to minimizing gate leakage in future high- $\kappa$ devices.

The infrared work was supported by and performed at Agere Systems. M.M.F. was supported by a fellowship within the Postdoc Program of the German Academic Exchange Service (DAAD). The authors wish to thank J. W. Maes (ASM-B) for providing the $\mathrm{HfO}_{2}$ samples, E. Garfunkel and K. Raghavachari for stimulating discussions, and S. B. Christman and E. E. Chaban for technical support.

${ }^{1}$ A. W. Ott, J. W. Klaus, J. M. Johnson, and S. M. George, Thin Solid Films 292, 135 (1997).

${ }^{2}$ G. S. Higashi and C. G. Fleming, Appl. Phys. Lett. 55, 1963 (1989).

${ }^{3}$ E. P. Gusev, M. Copel, E. Cartier, I. J. R. Baumvol, C. Krug, and M. A. Gribelyuk, Appl. Phys. Lett. 76, 176 (2000).

${ }^{4}$ D. G. Park, H. J. Cho, K. Y. Lim, C. Lim, I. S. Yeo, J. S. Roh, and J. W. Park, J. Appl. Phys. 89, 6275 (2001).

${ }^{5}$ H. Bender, T. Conard, H. Nohira, J. Petry, O. Richard, C. Zhao, B. Brijs, W. Besling, C. Detavernier, W. Vandervorst, M. Caymax, S. De Gendt, J. Chen, J. Kluth, W. Tsai, and J. W. Maes, Extended Abstracts of International Workshop on Gate Insulator, IWGI 2001, IEEE Cat. No. 01EX537, p. 86.

${ }^{6}$ V. Cosnier, H. Bender, A. Caymax, J. Chen, T. Conard, H. Nohira, O. Richard, W. Tsai, W. Vandervorst, E. Young, C. Zhao, S. De Gendt, A. Heyns, J. W. H. Maes, M. Tuominen, N. Rochat, M. Olivier, and A. Chabli, Extended Abstracts of International Workshop on Gate Insulator, IWGI 2001, IEEE Cat. No. 01EX537, p. 226.

${ }^{7}$ B. W. Busch, O. Pluchery, Y. J. Chabal, D. A. Muller, R. L. Opila, J. R. Kwo, and E. Garfunkel, MRS Bull. 27, 206 (2002).

${ }^{8}$ L. G. Gosset, J. F. Damlencourt, O. Renault, D. Rouchon, P. Holliger, A. Ermolieff, I. Trimaille, J. J. Ganem, F. Martin, and M. N. Semeria, J. Non-Cryst. Solids 303, 17 (2002).

${ }^{9}$ M. L. Green, M.-Y. Ho, B. Busch, G. D. Wilk, T. Sorsch, T. Conard, B. Brijs, W. Vandervorst, P. I. Räisänen, D. Muller, M. Bude, and J. Grazul, J. Appl. Phys. 92, 7168 (2002).

${ }^{10}$ M. M. Frank, Y. J. Chabal, and G. D. Wilk, Appl. Phys. Lett. 82, 4758 (2003).

${ }^{11}$ M. M. Frank, Y. J. Chabal, and G. D. Wilk, Mater. Res. Soc. Symp. Proc. 745, N2.4.1 (2003).

${ }^{12}$ I. J. R. Baumvol, Surf. Sci. Rep. 36, 1 (1999).

${ }^{13}$ As no suitable plateau was found in the cross-section curve of a nuclear reaction on ${ }^{27} \mathrm{Al}$, NRP was used instead of nuclear reaction analysis.

${ }^{14}$ Y. J. Chabal, G. S. Higashi, K. Raghavachari, and V. A. Burrows, J. Vac. Sci. Technol. A 7, 2104 (1989).

${ }^{15}$ T. Hattori, T. Aiba, E. Iijima, Y. Okube, H. Nohira, N. Tate, and M. Katayama, Appl. Surf. Sci. 104/105, 323 (1996).

${ }^{16}$ Small signals in the $\mathrm{C}-\mathrm{H}$ stretch region are consistent with instrumental instabilities arising from hydrocarbons in the optical path.

${ }^{17}$ K. T. Queeney, M. K. Weldon, J. P. Chang, Y. J. Chabal, A. B. Gurevich, J. Sapjeta, and R. L. Opila, J. Appl. Phys. 87, 1322 (2000).

${ }^{18}$ W. Mozgawa, M. Sitarz, and M. Rokita, J. Mol. Struct. 512, 251 (1999).

${ }^{19}$ F. De Smedt, C. Vinckier, I. Cornelissen, S. De Gendt, and M. Heyns, J. Electrochem. Soc. 147, 1124 (2000).

${ }^{20}$ W. J. Royea, A. Juang, and N. S. Lewis, Appl. Phys. Lett. 77, 1988 (2000).

${ }^{21}$ R. L. Puurunen, M. Lindblad, A. Root, and A. O. I. Krause, Phys. Chem. Chem. Phys. 3, 1093 (2001). 